\title{
Popular Education as a collective practice of insurgency and emancipation
}

\section{Educação Popular como prática coletiva de insurgência e emancipação}

\section{La Educación Popular como práctica colectiva de insurgencia y emancipación}

\author{
Ian Gabriel Couto Schlindwein ${ }^{1}$ iD , Carolina de Roig Catini ${ }^{1}$ (iD \\ ${ }^{1}$ Universidade Estadual de Campinas, Campinas, São Paulo, Brasil. \\ Autor correspondente: \\ Ian Gabriel Couto Schlindwein \\ Email: iangabrielcs@hotmail.com \\ Como citar: Schlindwein, I. G. C., \& Catini, C. R. (2021). Popular Education as a collective practice of insurgency and \\ emancipation. Revista Tempos e Espaços em Educação, 14(33), e14279. \\ http://dx.doi.org/10.20952/revtee.v14i33.14279
}

\begin{abstract}
This article investigates the original meanings of the term popular education in Latin America, whose polysemy acquired along the historical process imposes inaccuracies and obstacles to the educational debate. The guiding thread of the article is an interview with Carlos Rodrigues Brandão, for whom popular education is the work and militancy of a "thinking community", which aims at a revolutionary process, whose liberation is the first matter of an education that is not characterized only by addressing the popular class. The origin of this tradition in the context of the 1960s, first in the effervescence of Latin American popular movements and revolutions, and then organized as resistance and fight against dictatorships, places this popular education as an insurgent practice, of organization and confrontation against the State. The text is one of the results of a research carried out through historiographic and bibliographic study, as well as interviews and conversations conducted with popular educators.
\end{abstract}

Keywords: Popular Education. Latin America. Popular Culture. Emancipation. Liberation.

\section{RESUMO}

O presente artigo investiga os sentidos originários do termo educação popular na América Latina, cuja polissemia adquirida no processo histórico impõe imprecisões e obstáculos ao debate educacional. Seu fio condutor é uma entrevista realizada com Carlos Rodrigues Brandão, para quem a educação popular é trabalho e militância de uma "coletividade pensante", que tem como alvo um processo revolucionário, cuja libertação é matéria primeira de uma educação que não se caracteriza somente por se dirigir à classe popular. A origem dessa tradição no contexto dos anos 1960, 
primeiro na efervescência dos movimentos populares e revoluções latino-americanas e, em seguida, organizada como resistência e luta contra as ditaduras, situa essa educação popular como prática insurgente e emancipatória, de organização e confronto contra o Estado. O texto é um dos resultados de pesquisa realizada por meio de estudo historiográfico e bibliográfico, bem como de entrevistas e conversas realizadas com educadores populares.

Palavras-chave: Educação Popular. América Latina. Cultura Popular. Emancipação. Libertação.

\section{RESUMEN}

Este artículo investiga los sentidos originarios del término educación popular en Latinoamérica, cuya polisemia adquirida en el proceso histórico impone imprecisiones y obstáculos al debate educativo. Su hilo conductor es una entrevista a Carlos Rodrigues Brandão, para quien la educación popular es trabajo y militancia de una "colectividad pensante", que apunta a un proceso revolucionario, cuya liberación es materia prima de una educación que no se caracteriza solamente por dirigirse a la clase popular. El origen de esta tradición de los años 1960, primero en la efervescencia de los movimientos populares y revoluciones latinoamericanas y, en seguida, organizada como resistencia y lucha contra dictaduras, sitúa esta educación popular como una práctica insurgente y emancipadora, de organización y confronto contra el Estado. El texto es uno de los resultados de una investigación realizada a través de estudio historiográfico y bibliográfico, así como de entrevistas y conversaciones con educadores populares.

Palabras clave: Educación popular. Latinoamerica. Cultura Popular Emancipación. Liberación.

\section{INTRODUÇÃO}

Quando utilizamos o termo educação popular podemos estar nos referindo a uma grande variedade de sentidos, perspectivas, metodologias, posições, objetivos e práticas de educação das classes populares (Brandão, 1984; Mejía, 1989b), as quais, por sua vez, mantém diferentes graus de distanciamento da educação hegemônica e tradicional. A expressão é carregada de grande polissemia, compreende e é incorporada por práticas discursivas que representam diversos interesses, tempos e espaços sociais (Jara, 2006). Deste modo, as distinções por vezes não se observam nem mesmo no interior dos discursos e experiências específicas produzidas em cada contexto, quanto mais no uso genérico que muitas vezes se faz em formulações teóricas.

Contudo, a abrangência de enunciados de práticas designados como educação popular não é consensual e isenta de disputas. Em entrevista, realizada em março de 2019, o professor e educador popular Carlos Rodrigues Brandão aponta o risco e também a dificuldade da utilização do termo, principalmente no que toca a grande variedade de perspectivas políticas que ele pode abranger:

Eu quase que diria: você abre um leque quando você fala educação popular em alguma coisa que, por exemplo, à direita, mais à direita do gradiente, quase vai ser próxima da educação social. Quer dizer, é uma educação de sensibilidade popular, que tem um certo lado de um projeto iluminista, ou seja, educar, alfabetizar, para ilustrar ou para torná-lo cidadão. E aí com focos em questão de gênero, em questão ambiental, de acordo com o contexto que você está trabalhando. Até uma posição mais, digamos assim, à esquerda do gradiente, que vai tangenciar com a ideia de educação como prática revolucionária. Ou seja, tudo o que se faz junto ao povo é para preparar para uma transformação radical da realidade (Brandão, Entrevista, 2019).

A educação popular, assim, ganha características políticas que podem situá-la desde a esfera da educação social até uma educação revolucionária, identificadas como gradações que vão da 
direita para a esquerda do campo. Diante desse leque heterogêneo, contraditório e dinâmico, o artigo tem por objetivo precisar uma certa tradição latino-americana desenvolvida dentro do que genericamente é chamado de educação popular, dando contornos mais precisos ao caráter emancipatório dessa forma de educação, relacionada a um posicionamento "à esquerda do gradiente" destacado por Brandão.

Essa caracterização permite diferenciar de modo consistente uma educação que continua a aparecer em práticas e processos de educação que Brandão (Entrevista, 2019) chama de "insurgentes ou emancipadores. Liberadores, se quiser usar uma expressão de Paulo Freire", que além de ter o povo "como um sujeito substantivo do processo", tem um objetivo "profundamente transformador da realidade social". Ademais, "como ela se desenvolveu muito mais em países do terceiro mundo e do Ocidente, ela se tornou profundamente, primeiro anticapitalista, no nosso tempo, e depois anticolonialista" (Brandão, Entrevista, 2019). Deste modo, se por um lado, é a prática que se relaciona com o enorme campo da educação popular, repleto de posicionamentos distintos e conflituosos, por outro se circunscreve no interior de uma longa tradição de pedagogias críticas e/ou emancipatórias. Ou seja, não se trata simplesmente de uma educação voltada às classes populares, mas especialmente uma educação relacionada com as lutas e reivindicações contra hegemônicas construídas coletivamente durante a história dos territórios de nosso continente.

O confronto e o antagonismo ficam evidenciados pela materialidade da origem da educação popular da América Latina, sobretudo aquela que se forja propriamente a partir dos anos 60 do século passado. Podemos dizer que essa tradição se desenvolvia a favor da história no Brasil, se opondo sobretudo ao caráter elitista e excludente do sistema educacional brasileiro, mas que passou a desenvolver-se à contrapelo com a dura interrupção de um processo histórico marcado pelo Golpe Militar de 1964. Se essa ambivalência a favor e contra à ordem fazem parte se sua origem, o horror das ditaduras latino-americanas deixou marcas profundas que lhe conferem um forte sentido de confronto. No contexto em que vivemos, nos parece relevante acentuar essa característica de combate, completamente avessa à contenção social, e produtora de relações entre trabalhadoras e trabalhadores de coletividade, organização e luta.

O texto tem por objetivo situar essa tradição de Educação Popular ${ }^{1}$ com base no estudo do contexto de sua emergência, trabalhando alguns resultados de um conjunto de investigações realizadas nos últimos anos. Em especial, aos estudos presentes na dissertação $A$ educação popular sob o céu da história ${ }^{2}$ (Schlindwein, 2020), que buscou, a partir de revisão bibliográfica e de entrevistas com educadores populares, articular a história da educação popular em seu sentido emancipatório - fundamentalmente entre as décadas de 1960 e 1980, relacionando o contexto brasileiro com o restante da América Latina - com a noção de rememoração, tal como formulada por Walter Benjamin. A base do estudo foi uma pesquisa qualitativa, que aliou o levantamento e a análise de uma bibliografia relacionada, no interior do recorte estipulado, à processos de rememoração nas lutas das classes oprimidas e nos movimentos populares latino-americanos com a sistematização e reflexão de experiências de educação popular no continente a partir de entrevistas com educadores populares ${ }^{3}$ que não só atuaram como também produziram materiais analíticos sobre esse campo nas últimas décadas. A partir desse leque de análises, foi possível traçar aproximações e distanciamentos entre as formas de compreensão da história dessa educação

\footnotetext{
${ }^{1}$ A grafia com as iniciais em maiúscula compreende não o sentido mais abrangente da expressão, mas sim seu uso quando relacionado com posicionamentos à esquerda que tencionam para um horizonte revolucionário e/ou emancipatório (Brandão, 1984).

${ }^{2}$ A pesquisa de metrado foi financiada pela Fundação de Amparo à Pesquisa do Estado de São Paulo (FAPESP), processo 2017/14221-0, e pela CAPES.

${ }^{3}$ Mais especificamente os educadores Carlos Rodrigues Brandão, Oscar Jara e Mario Garcés. As entrevistas tiveram como base os aportes metodológicos das perspectivas da Memória Social e da História Oral (Bosi, 2003; Lang et al., 2010).
} 
popular - levando em conta perspectivas internas e externas aos movimentos - com o conceito de rememoração e a análise da história tendo em vista a perspectiva benjaminiana.

A partir de um recorte dessa investigação, tendo como fio condutor uma entrevista realizada com Carlos Rodrigues Brandão em março de 2019, o presente artigo discute orientações políticas de práticas educação relacionadas às lutas e aos movimentos de cultura popular, os quais ocuparam uma centralidade nas disputas de projetos de sociedade num período de grande radicalização.

\section{A EDUCAÇÃO ASSINADA COMO POPULAR}

Como parte de sua pesquisa de doutorado ${ }^{4}$, o sociólogo e educador popular peruano e costarriquenho Oscar Jara investigou o surgimento do uso do termo Educação Popular, com foco principalmente na memória dessa tradição com sentido emancipatório construído nos anos 1960. A mais antiga publicação regular que ele encontrou nesse sentido relacionado aos movimentos de cultura popular foi a série chilena Cuadernos de Educación Popular, escrita por Marta Harnecker e Gabriela Uribe (1972) e publicada durante o período da Unidad Popular pela Editora Nacional Quimantú, sendo os dois primeiros cadernos - de um total de doze - lançados em dezembro de 1971. Dada a suspeita da existência de usos mais antigos, particularmente em práticas e movimentos, ele partilhou esse questionamento com Carlos Rodrigues Brandão, que colocou a pergunta a um grupo de outras pessoas relacionadas ao campo ${ }^{5}$, numa busca e discussão coletiva sobre o assunto, como o educador brasileiro aponta em depoimento:

[...] o Oscar Jara, justamente, por conta da tese de doutorado dele, me pergunta: "onde é que pela primeira vez aparece educação popular escrito?". E eu pensei que fosse muito fácil. Aí comecei a procurar com ele, porque eu também fiquei curioso. Eu descobri que não tinha em lugar nenhum. Pedi para várias pessoas amigas, Osmar Fávero, o Danilo Streck, a Fernanda Paulo, que estava fazendo tese, e mais a Maria Teresa Sirvent na Argentina, Norma Michi: "Gente, quem de vocês sabe?". Ninguém sabia. Quem levantou uma lebre importante foi o Osmar Fávero, que é a grande memória da Educação Popular, porque ele disse que a primeira vez que aparece por escrito é numa sigla. É um movimento da Paraíba, CEPLAR [...] (Brandão, Entrevista, 2019).

Um dos principais movimentos de alfabetização popular do Nordeste, a CEPLAR - Campanha de Educação Popular foi criada em 1961 no estado da Paraíba, onde o índice de analfabetos chegava a $65 \%$ da população (Scocuglia, 1999). Diferentemente do SIREPA ${ }^{6}$ e da Cruzada $A B C^{7}$, se posicionou radicalmente à esquerda desde seu nascimento, fazendo uso pioneiro do Método Paulo Freire, no bojo das reformas de base e de uma perspectiva que denominava "revolução pelo voto". Já com influência do Movimento de Cultura Popular, esteve em diálogo direto com Paulo Freire - que, em atividades de formação de educadores e educadoras, orientou a mudança do foco inicial do trabalho pedagógico, até então voltado a crianças - e sua equipe do Serviço de Extensão Cultural da Universidade do Recife a partir de 1962 (Lustosa, 2018). O movimento, formado principalmente por estudantes secundaristas e universitários, integrou tanto alas da Igreja - especialmente jovens

\footnotetext{
${ }^{4}$ Cuja tese foi defendida em 2017 na Universidad de Costa Rica e posteriormente serviu como base para o livro La Educación Popular Latinoamericana: Historia y claves éticas, políticas y pedagógicas, sendo sua primeira edição publicada em 2018 na própria Costa Rica pelo Centro de Estudios y Publicaciones Alforja (Jara, 2020).

${ }^{5}$ Do qual também participaram Danilo Streck, Baldoino Andreola, Fernanda Paulo, Norma Michi, Marco Raúl Mejía, Eymard Vasconcelos, Marcos Arruda, Gaudêncio Frigotto, Osmar Fávero, Moacir Gadotti e Camila Teo (Brandão, $2015 a$ ). ${ }^{6}$ O Sistema Rádio Educativo da Paraíba atuou entre 1959 e 1969 através do método de alfabetização-educação de adultos por meio do rádio, instigando a desmobilização política (Scocuglia, 1999).

${ }^{7}$ A Cruzada de Ação Básica Cristã - administrada por missionários protestantes, apoiada pela elite regional e financiada por técnicos dos EUA - inicialmente objetivava neutralizar o método político-pedagógico da CEPLAR. Durante a ditadura sua ação foi expandida para outros estados nordestinos (Scocuglia, 1999; Lustosa, 2018).
} 
vinculados à Ação Católica através da JUC, JEC e AP ${ }^{8}$ - quanto membros ligados ao PCB. Durante sua breve existência, a CEPLAR

transitou entre os objetivos desenvolvimentistas e revolucionários; entre alianças com o Estado e com movimentos sociais camponeses; entre a influência da Igreja e a do Partido Comunista. Não sendo possível afirmar aqui a existência de uma orientação ideológica que tenha exercido supremacia no/sobre o movimento. A Ceplar se situou numa confluência política de várias instituições e organizações. Contudo, é possível afirmar que o contato com as Ligas Camponesas e com o Partido Comunista redimensionou os objetivos iniciais da Ceplar (Ibid., p. 143).

Como salienta Kelyana da Silva Lustosa (2018), desde seu estatuto publicado em abril de 1962, que oficializou suas atividades perante o governo estadual, a CEPLAR buscava - através de práticas pedagógicas, de alfabetização popular e teatro, "elevar" o nível cultural do povo, trabalhando para a formação de "quadros" preparados para interpretar, sistematizar e transmitir elementos presentes na cultura popular. Em março de 1964, haviam 135 círculos de cultura somando cerca de quatro mil educandos entre João Pessoa, Campina Grande e junto à Ligas Camponesas em municípios como Rio Tinto, Mari e Sapé. A CEPLAR se viu obrigada a cessar suas atividades logo depois do golpe, alvo de perseguição e acusação de implementar um embrião revolucionário na Paraíba. Alguns de seus membros já sofreram detenção logo na noite entre 31 de março e 1ㅇde abril (Scocuglia, 1999; Lustosa, 2018).

Osmar Fávero, durante o diálogo iniciado por Oscar Jara e Carlos Rodrigues Brandão, chamou a atenção para o movimento semântico no início da década de 1960, no qual de cultura popular derivaram diversos termos, como notoriamente teatro popular, cinema popular e música popular. O mesmo pode ser compreendido no campo da educação, sendo que aos poucos a expressão Educação Popular foi se consolidando em diversas práticas e, também, no campo teórico. Em sua pesquisa, Oscar Jara, entretanto, não estava apenas preocupado com a primeira vez que o termo havia sido utilizado no contexto dos movimentos influenciados pelos debates em torno da cultura popular, mas também como este se disseminou e se tornou tão influente ao ponto de se generalizar em tantas experiências pelo continente.

Aí um dia o Oscar me manda uma mensagem dizendo assim: "Brandão, essa tua pesquisa está muito esquisita, porque você mesmo não descobriu. Onde a expressão aparece pela primeira vez escrita num livro é num livro teu". Que é esse livro aqui. Que saiu com esse nome do Júlio Barreiro, porque a gente resolveu colocar com o nome dele. É um teólogo protestante que morreu [...].

Dez anos depois eu saí como tradutor do meu próprio livro. Aí tem até a cartinha do Júlio Barreiro.

E segundo Oscar Jara, eu não concordo muito com ele não, mas ele falou que a primeira vez que essa expressão aparece grafada assim é nesse livro. Paulo Freire usava educação conscientizadora, problematizadora, liberadora e libertadora. O MEB, onde trabalhei e me iniciei, Movimento de Educação de Base, cunhou educação de base. Mas Educação Popular foi tardio, não é? E Paulo mesmo pouco usou. Tanto que em nenhum livro dele tem, a não ser em entrevistas. Aí ele solta. Ele trabalha mais com pedagogias, não é? Com pedagogia do oprimido, da esperança, da indignação, da autonomia (Brandão, Entrevista, 2019).

Educação popular e conscientização é o título do livro que Brandão menciona. Entre o fim dos anos 60 e início dos 70, Brandão fez parte de um grupo de educadores - do qual também participavam Beatriz Costa, Jether Pereira Ramalho e Elter Dias Maciel - vinculada ao Centro

\footnotetext{
${ }^{8}$ Respectivamente Juventude Universitária Católica, Juventude Estudantil Católica e Ação Popular.
} 
Ecumênico de Informação ${ }^{9}$. Constavam entre as ações clandestinas viagens pela América Latina para disseminar e assessorar grupos de alfabetização e educação popular. Diversos grupos ecumênicos, dentre os quais o CEI, se conectavam em rede a partir da ISAL - Igreja e Sociedade na América Latina $^{10}$. Se constitui, então, trabalhos de formação e difusão dessa nova perspectiva de educação através do programa Educación para la Justicia Social, com agentes pastorais de diferentes países (Jara, 2020). A obra em questão sistematizava tais práticas e, por conta da perseguição política e dos riscos de ser assinado por um educador popular brasileiro durante a ditadura, o livro é creditado ao teólogo, professor universitário e advogado militante uruguaio Júlio Barreiro, também membro da ISAL (Brandão, 2015a; 2015b). Originalmente lançada em 1974 pelo Editorial Siglo XXI, de Buenos Aires, Educación Popular y proceso de concientización é uma síntese de diversas experiências latinoamericanas:

De um lado as suas páginas não teriam justificativa alguma se não procurassem refletir aquilo que as antecedeu, ou seja, a prática da educação popular, em grupos de base da mais variada precedência social e mesmo nacional, levada a cabo em vários países da América do Sul durante um período superior a vinte e quatro meses. Por outro lado, recolhem, com o maior rigor possível, uma tentativa de sistematização dessas experiências e dos diversos e possíveis modelos que iam surgindo ao longo delas, às vezes muito além das intenções e dos objetivos daqueles que, como nós, vivem aquela prática educativa (Barreiro, 1980, p. 11).

Embora as práticas estivessem profundamente marcadas pela trajetória de Paulo Freire, que como lembra Carlos Rodrigues Brandão praticamente não utilizava este termo Educação Popular, há indícios de que o motivo do amplo uso dessa expressão esteve mais ligado aos tantos movimentos e processos de organização popular presentes pela América Latina. Em outro momento, Brandão (2015a, p. 32) também destaca tal aspecto: "Lembro que quando em nome do CEDI fizemos aquele rosário de viagens pela América Latina, começando por Buenos Aires em 1969, espalhando as ideias de Paulo Freire, a expressão "educação popular" já era corriqueira. E ela está no título do livro de Júlio Barreiro".

Para Fernanda Paulo (2018), a obra Educação Popular e conscientização é expressão da prática educativa e do conhecimento que estava sendo produzido na passagem entre as décadas de 1960 e 1970. A produção escrita a partir das experiências da viagem lhe oferece um caráter profundamente latino-americano, para além das fronteiras entre os países. A sistematização de experiências tinha por objetivo produzir conhecimentos efetivamente populares advindos das práticas e das ações políticas transformadoras, em conflito e oposição às propostas ideológicas do poder hegemônico (Barreiro, 1980). Comentando tal debate, Oscar Jara (2020, p. 119) aponta que:

La relevancia de este libro, entre otros aspectos, reside en que constituye una de las primeras fundamentaciones teóricas explícitas de lo que es una "Educación Popular" desde su sentido político, que se inspira en los aportes de la filosofía educativa freiriana, pero los amplía con elaboraciones proprias y con referencias de otros autores de la filosofía y ciencias sociales. Por otra parte, desarrolla con mucho detalle el proceso de "concientización" y su perspectiva de descubrimiento de la persona humana, vinculándola con dos aspectos innovadores: el vínculo del conocimiento popular y consciencia de clase [...]. Podemos afirmar que fue este equipo animado por Carlos Rodrigues Brandão, el principal responsable que a la corriente de educación libertadora se le comenzara a denominar, desde entonces, "Educación Popular".

\footnotetext{
${ }^{9}$ Foi fundado logo após o golpe de 64 como Centro Evangélico de Informação. No ano de 1968 teve seu nome alterado uma primeira vez, após a incorporação de militantes católicos de organizações que haviam sido perseguidas ou desmanteladas. Já em 1974 foi novamente rebatizado, agora como CEDI - Centro Ecumênico de Documentação e Informação (Costa, 2010).

${ }^{10}$ Movimento que desde 1961 operava junto ao Conselho Mundial de Igrejas (Costa, 2010; Jara, 2020).
} 
Apesar de reutilizar um termo presente desde o século XIX na América Latina, a reinvenção de seu significado no século XX se distancia de projetos que tinham semelhança com perspectivas "iluministas", isto é, que se voltavam para "oferecer", "conceder" formação ilustrada e baseada na razão científica e com caráter nacional à toda população. É preciso lembrar que mesmo Simon Rodríguez (2017, p. 170), um dos defensores de uma "Educação Popular" no século XIX na América Latina já apontava para as dificuldades relativas ao significado do termo popular como algo que defina qualidades de uma dada prática de educação. Diz ele: "El proyecto de Educación Popular tiene la desgracia de parecerse á lo que, en varias partes, se ha emprendido con este nombre - y se practica, bajo diferentes formas, con un corto número de individuos, sobre todo en las grandes capitales". Ou seja, as concepções de educação popular já estavam em disputa desde então ${ }^{11}$.

\section{A EDUCAÇÃO POPULAR COMO MOVIMENTO DE CULTURA E POLÍTICA}

Os processos de Educação Popular - enquanto produtos da conflitiva história da região que usualmente chamamos de América Latina, em particular na trajetória de seus movimentos populares (Jara, 2020) - se relacionam com as diversas raízes que os constituiu. A concepção freiriana de educação especificamente se forma enquanto campo a partir da síntese de experiências que vinham sendo abordadas - teórica e praticamente - nas décadas anteriores e mesmo desde as entranhas dos séculos de violências e resistências presentes em realidades permeadas pelo colonialismo e capitalismo.

Em meados do século passado, estes processos se inscreveram dentro de conflitos relacionados com a Guerra Fria. Nesse período de ebulição, o continente esteve tensionado por dois polos mais visíveis: o da reforma capitalista do capitalismo, voltado para o aprofundamento visceral da ordem vigente; e o da revolução contra a ordem, pautado nesse momento especialmente pelas perspectivas socialistas e vinculado à busca pela consolidação de rebeliões de cunho popular (Fernandes, 2009). Nesse sentido, a Revolução Mexicana foi uma espécie de anúncio das dinâmicas de revoluções e contrarrevoluções, insurgências e contra insurgências que acompanharam o século. Contudo, mesmo com a radicalização de dois polos opostos - relacionados na geopolítica mundial respectivamente às potências EUA e URSS - os antagonismos não ficam necessariamente tão evidentes nas dinâmicas das práticas sociais, que por vezes se mesclam no interior de uma mesma organização política, como formas de manifestações complexas no continente (Romão, 2014). Essa relação conflituosa se evidencia no próprio nascimento da Educação Popular, marcada pela ambivalência entre sua relação com a Educação de Adultos ${ }^{12}$, voltada à modernização das forças produtivas e usualmente relacionada à esforços refinados de uma educação para as classes populares regada pelos interesses e objetivos de elites regionais, nacionais e internacionais, organizações religiosas, governos, organismos internacionais etc.; mas também por novos horizontes de transformação da realidade ancorados em projetos e utopias contra hegemônicos e revolucionários, que se mostravam cada vez mais palpáveis.

Nesse contexto alguns fatores terão destaque para a formação desse sentido emancipatório de educação popular no continente, como: a transformação e ampliação das perspectivas políticas por conta da Revolução Cubana; processos relacionados ao posicionamento da Igreja Católica,

\footnotetext{
11 Mesmo anteriormente é possível encontrar diferentes usos do termo educação popular, como no contexto de efervescência dos ideais iluministas na Revolução Francesa (Mejía, 1989b) - que teve grande influência nos processos de independências e nas formações das repúblicas latino-americanas - ou mesmo mais de dois séculos antes, no cenário da Reforma Protestante, quando a expressão esteve presente em grupos religiosos de regiões da atual Alemanha, em processos de ensino da leitura a partir de passagens bíblicas (Paulo, 2018).

${ }^{12}$ Após a Segunda Guerra Mundial, os programas de Educação de Adultos surgem como uma forma mais elaborada de educação para as classes populares que buscaram neutralizar as formas de educação de classe que, especialmente durante o início do século XX, se disseminaram por muitos países do continente a partir das organizações sindicais.
} 
sobretudo depois do Concílio do Vaticano $\|^{13}$; a ampliação e diversificação de projetos e organizações socialistas (Mejía, 1989a); além de múltiplos eventos político-culturais contra hegemônicos que se influenciavam mutuamente, dos quais poderíamos citar brevemente as lutas de libertação nacional em países periféricos, manifestações, greves e revoltas protagonizadas por trabalhadores e estudantes, ascensão de movimentos contraculturais ${ }^{14}$ etc. (Ridenti, 2018). Esses elementos foram fundamentais para a efervescência e centralidade de movimentos de cultura popular na América Latina durante os anos 60.

Nessa forma de cultura - em relação conflitiva com a cultura erudita, que se mostrou historicamente uma forma de legitimação das classes dominantes, naturalizando e tornando hegemônicos seus interesses perante o restante da sociedade (ECO, 2012) - o termo

\begin{abstract}
"Popular" pode traduzir aquilo que, por oposição ou distanciamento do que é "erudito", é algo criado e vivido por atores e autores das "camadas populares de uma sociedade". E "camadas populares" depressa vai ser ideológica e politicamente associado a "explorado, "marginalizado", "oprimido", "subalterno", "o povo" e, mais adiante, a "classe popular" e seus afins: "proletariado", "operariado", "campesinato".

[...] Ainda em uma dimensão próxima, "popular" pode significar o que se cria, preserva, difunde, partilha e transforma em diferentes esferas e por ação de diversos estratos sociais no domínio da sociedade civil, por oposição ao que é criado e controlado diretamente por um poder de estado, ou pelo setor empresarial de uma sociedade (Brandão, 2015a, pp. 30-31).
\end{abstract}

Nos movimentos de cultura popular que compõem o espectro que é objeto de nosso estudo "[...] não existe ninguém mais culta do que outra, existem culturas paralelas distintas, que se complementam na vida social" (Betto, 2008, p. 6). Assim, não há cultura à margem da vida social ou sujeitos sem cultura (ECO, 2012). A cultura popular é dinâmica, diversa e consegue movimentar diferentes elementos pertencentes à distintas realidades, em sociedades desiguais nas quais as classes dominantes tentam impor uma cultura reflexa, ou alienada, em contraposição a uma cultura de reflexão. Assim, não podemos perder de vista a complexidade e ambiguidade das culturas das classes populares, por possuírem um conjunto de elementos com significados resguardados e dinamizados pela própria classe popular, de forma relativamente autônoma; e que também incorpora elementos externos, impostos pela cultura dominante (Brandão, 2002).

Os movimentos de cultura popular fizeram uso de diversas linguagens - música, literatura, artes plásticas, dança, cinema, teatro, educação etc. - com sentido de reposicionar uma classe popular que produz cultura e disputa de leituras históricas com processos hegemônicos e dominantes. Essa concepção esteve presente em muitos países latino-americanos, relacionada a realidades heterogêneas, tecendo relações em contextos diversos, mas permeado por um sentido comum que se forjava pela produção de cultura para um dado confronto. Entretanto, o tecido comum também se tramava a partir de características dominantes do processo, uma vez que eram partilhadas por uma vida social marcada por governos reformistas, pelo sentido da modernização das forças produtivas, dos processos acelerados de industrialização e urbanização em conjunto com as transformações nos costumes, a radicalização de movimentos conservadores etc.

Os movimentos relacionados a este campo se formam da síntese de experiências e das contradições de um período repleto de transformações, que no Brasil se evidencia desde a crescente organização popular ao redor do campo cultural e também com relação às reformas de base propostas durante o governo de João Goulart até o golpe de 64 e na sucessiva ditadura.

\footnotetext{
${ }^{13}$ Convocado pelo Papa João XXIII e realizado entre 1962 e 1965, teve como objetivo abordar de forma ampla a necessidade de renovação e atualização de aspectos da Igreja frente às rápidas transformações técnicas e políticas ocorridas desde o século XIX, principalmente no que toca a primeira metade do século posterior.

${ }^{14}$ Especialmente os relacionados a pautas como os direitos civis de grupos marginalizados, o feminismo, a liberdade sexual, a liberdade de expressão, o pacifismo etc.
} 
Vinculado a manifestações continentais mais amplas, movimentos culturais desse período em nosso país, em grande medida, tinham sua pedra angular nos processos educativos, sobretudo na educação de adultos, voltadas para alfabetização. Esses movimentos estiveram profundamente relacionados a um período de grande crise da hegemonia econômica e política, que também significou um avanço da organização e mobilização de operários e camponeses no cenário político do país, sobretudo no Nordeste, com particular destaque para a ascensão e consolidação das Ligas Camponesas ${ }^{15}$.

Muitos interesses convergiam em torno da educação de adultos neste momento histórico de disputa de projetos nacionais representado por partidos políticos. O voto restrito a quem sabia ler e escrever excluía boa parte das pessoas da escolha eleitoral, de modo que acabava por dinamizar a "mobilização em prol da alfabetização do povo", de acordo com Sílvia Manfredi (1978, p. 26), uma vez que ela "poderia garantir aos líderes populistas a ampliação do eleitorado, aumentando assim as bases de sustentação de seu poder". As desigualdades sociais tinham expressão mais grave nas regiões mais pobres do país, nas quais foram incentivadas práticas de educação voltadas à participação política de significativo contingente populacional (Germano, 1997). De um lado, havia propostas fortemente ligadas às reformas do governo Jango, porém também haviam outras que buscavam ampliar e transformar radicalmente os horizontes políticos preestabelecidos (Torres, 1992), se aproximando mais das práticas revolucionárias presentes no continente.

Para estes militantes cuja prática escapava aos limites do projeto eleitoral de mudanças pelas reformas estatais, havia a compreensão de que existia um movimento intrinsicamente político - e de potencial transformador e libertador - no qual a cultura popular se apresenta como instrumento educativo e a educação é momento do processo cultural (Brandão, 2002; 2018). A atuação buscava, portanto, a formação de indivíduos e grupos politicamente ativos e voltada para uma outra configuração do poder popular no interior dessa sociedade, ou mesmo de outra, por vir. Os integrantes de diferentes experiências de alfabetização que compartilhavam dessa visão possuíam, então, um horizonte político mais radical do que o apresentado em modelos tradicionais de Educação de Adultos ${ }^{16}$.

De qualquer forma, de acordo com Carlos Rodrigues Brandão, no início da década de 1960, a ideia de cultura popular era a principal e mais visível base das práticas educativas:

A questão é que não se fala de educação popular. O que nos unia era cultura popular. 0 primeiro encontro nacional de movimentos de cultura popular foi, se não me engano, em 62 , janeiro de 62, organizado pela equipe do Paulo Freire no Recife. Então eram os MCPs - Movimentos de Cultura Popular e os CPCs - Centros Populares de Cultura. Eu cheguei até a fazer um curso deles, lá no Rio de Janeiro, na UNE. No prédio da UNE. [...] E é interessante que era um movimento que agregava artistas, músicos, pessoal de teatro, gente da área de saúde e até educadores, como eu costumo dizer. Aí então a gente usava a expressão alfabetização popular, que era um trabalho concreto, inclusive muito de inspiração freiriana. Eu mesmo escrevi os primeiros trabalhos explicando o Método Paulo Freire. Inclusive em espanhol fui eu que escrevi. Então o que nos congregava era cultura popular. Era muito comum nos anos 60 , você via dois estudantes conversando, um dizendo para o outro: "Você está estudando o que?". "Ah eu tô fazendo Direito". "E você tá lidando com que área?". "Ah com cultura popular". "Ah legal rapaz! Em que área?". "Ah eu tô mexendo com teatro. E você?". "Eu tô mexendo com cinema". E por aí vai... É

\footnotetext{
${ }^{15}$ Que surgiram em meados da década de 1950 e rapidamente se tornaram importantes e influentes organizações em defesa dos interesses da classe trabalhadora rural, especialmente em sua luta pela reforma agrária.

${ }^{16}$ Diferentemente de uma Educação Popular fundamentada em "[...] uma maior inadequação ao sistema opressor e, ao mesmo tempo, uma adequação maior aos processos através dos quais se mobiliza a ação transformadora" (Barreiro, 1980, p. 23, grifos do autor), quase todos os programas tradicionais de Educação de Adultos buscam adequar a vida dos indivíduos das classes populares ao sistema que os oprime. Em suma para que esses grupos possam "[...] modificar-se para que o sistema sócio-político não precise transformar-se" (idem).
} 
muito interessante. E quando surge o próprio Paulo com a equipe dele nordestina, eles se colocam como pessoas trabalhando em cultura popular através da educação (Brandão, Entrevista, 2019).

O fato de que nas mobilizações em torno da cultura popular haviam "até educadores", como salientado por Brandão, expressa uma grande ramificação e capilaridade no que toca a preocupação de se aprofundar no cerne do cultural presente no Brasil. Assim, afinado à ebulição social do período, pretendia-se realizar ações vinculadas com a cultura popular a fim de forjar um povo capaz de elaborar, sistematizar e expressar críticas radicais à realidade vigente (Brandão, 2018).

\section{O LUGAR DA EDUCAÇÃO POPULAR}

No bojo de um movimento de transformações que buscavam ter como base as necessidades populares, a educação era tida como um caminho para romper com amarras imperialistas e de dependência. Os movimentos regados dessa perspectiva eram formados de "[...] um conjunto de forças sociais contestadoras das grandes e graves desigualdades existentes" (Manfredi, 2014, p. 368), que incluíam religiosos, estudantes, intelectuais, artistas, políticos, sindicalistas e militantes de movimentos sociais e populares em alianças - que não necessariamente possuíam grande organicidade - de ação cultural organizada (Paiva, 1987). A grande fragmentação da esquerda e suas inúmeras divisões contribuía para a variedade de experiências de educação popular, com diferentes fontes e raízes:

Então sempre foi algo criado em uma terra de ninguém. Tanto aqui no Brasil, quanto na América Latina. E inclusive você vê essa dubiedade no próprio Paulo Freire. O Paulo tem uma entrevista muito interessante, não sei se é pro Ira Shor, em que a pessoa pergunta: "Paulo, você é marxista?". E o Paulo com aquele jeitão dele diz: "Olha... Se você considerar marxismo um trabalho contra as injustiças, em favor da libertação da humanidade e a criação de um mundo mais justo, pode-se dizer que eu sou marxista". E aí a pessoa pergunta: "E cristão, você é?". Responde: "Bom... Se você considerar cristão..." e repete mais ou menos a mesma coisa: "Podese dizer que sou cristão". O Alfonso [Torres Carrillo] até em algum momento desse livro aqui [ $L a$ Educación Popular] aborda essa questão. Quer dizer, o Paulo sempre se colocou - e não foi de uma maneira astuta e safada não, de uma maneira extremamente coerente, basta você ler a bibliografia do Pedagogia do Oprimido - como um humanista. Não um humanista cristão.... Eu, por exemplo, fazia parte de um movimento cristão, a Juventude Universitária Católica, do MEB, que era cristão. Mas humanismo que fazia uma crítica social com base marxista, mas eu diria não até as últimas consequências. Por exemplo, a categoria luta de classe, em Paulo Freire, vai ser vaga. Embora a ideia de revolução esteja presente, não no Pedagogia do Oprimido, [mas] publicado mais na edição fac-símile. Ele fazia até um esquema da ação revolucionária. Então isso é muito interessante porque há diferença [...] de outros verbetes que, por exemplo, [Gaudêncio] Frigotto vai estudar educação omnilateral, educação anarquista, educação isso e aquilo. A educação popular [é] originária nem de um grupo político, nem de uma tendência religiosa, nem sequer de uma ideologia única. Ela é uma leitura crítica, ela é uma leitura libertadora, para usar palavras do Paulo Freire, mas nunca filiada (Brandão, Entrevista, 2019).

Assim, desde os movimentos de cultura popular, a educação popular com sentido emancipatório se expressa sem manifestar um posicionamento único ou mesmo centralizado, embora possua referenciais marcantes. Ela não irá se filiar a uma orientação ou grupo político, mas referir-se a uma teoria e prática crítica e libertadora. Embora se destaque as tendências marxistas, havia dentro também distintas vertentes dos movimentos de cultura, alguns mais ligados aos cristãos e humanistas, outros à partidos e movimentos de base. As diferentes linhas socialistas presentes nos movimentos do período - que poderiam estar mais ou menos de acordo com os discursos oficiais do PCB ou propriamente do PCUS - contribuíram ainda mais para a grande 
pluralidade de referências e perspectivas que fizeram parte do berço da Educação Popular (Mejía, 1989a). De tal forma que Brandão, ao prosseguir com seu depoimento, salienta que o sentido emancipatório dessa forma de educação - ao mesmo tempo específica e tão ampla - possui um diferencial no que tange seu nascimento enquanto campo de atuação:

Então é preciso compreender a Educação Popular assim, ela surge, para usar uma expressão de antropologia, ela surge num não lugar. Ela surge num território entre fronteiras. Essa experiência dos anos 60. Também tem depois Teologia da Libertação, a IAP - Investigação Ação Participativa, que são vários brotes que justamente vão surgir... A Teologia da Libertação nem tanto, ela é marcadamente cristã, mas é fundamentalmente ecumênica. Não é católica só. Mas esses outros movimentos e criações, eles vão surgir justamente nesse entre lugares, nesse intervalo entre teorias marxistas várias. Eu me lembro nos anos 60 , você encontrava um marxista e logo tinha que se assinar se era trotskista, leninista ou maoísta. Era muito comum isso. E daí tive amigos fervorosamente maoístas. Então é o encontro de humanistas militantes cristãos definidamente, vários. Inclusive até o movimento ISAL - Igreja e Sociedade na América Latina, que é muito forte, eu participei dele. [...] Tinha inclusive o movimento de padres pelo socialismo, curas pelo socialismo, isso em 63. Leitores profundos de Marx, de Gramsci e tudo isso. E é interessante que então você tem de um lado essa vocação cristã humanista emancipadora, depois você tem, como até hoje, o que eu chamaria de humanistas leigos, não cristãos [...] e marxistas. Então uma espécie de encruzilhada (Brandão, Entrevista, 2019).

Este "não lugar", território permeado por várias fronteiras de orientações e grupos, se mostrou - mesmo abrangendo divergências consideráveis, principalmente entre marxistas e nãomarxistas - muito fecunda com relação a trocas de experiências, metodologias e informações entre os movimentos, especialmente com a organização de encontros regionais e nacionais. Isso se refletia num movimento constante de diálogo e reposicionamento dos grupos, de acordo com Vanilda Paiva (1987, p. 231):

Nessa busca de métodos e em sua justificação, refletiam-se as divergências políticas e ideológicas entre os grupos. Discutia-se o conceito de cultura popular, o papel da arte e da alfabetização, bem como a ênfase que cada uma delas deveria merecer e, finalmente, o problema da diretividade ou não-diretividade dos métodos, por trás do qual colocava-se a questão da manipulação das massas. Entretanto, apesar das divergências, os grupos influíram metodologicamente uns sobre os outros, e estas influências recíprocas provocaram diversos processos de revisão nos movimentos.

A partir desse diálogo, segundo Brandão (2002), alguns pressupostos se tornam mais comuns, como a compreensão de que: (a) o povo como o conjunto de grupos expropriados dos meios de produção; (b) existe relação estrutural entre as práticas de exploração e o domínio da cultura erudita sobre a popular; ocasionando uma alienação que ajuda a fundamentar a exploração; (c) os movimentos de cultura popular tem a conscientização como trabalho fundamental, ao passo que possibilitaria instrumentalizar politicamente as organizações voltadas à construir um poder popular; e (d) os mesmos movimentos precisam estabelecer um lugar comum para militantes mais ligados à erudição intelectual quanto às culturas populares. Dentre a multiplicidade de organizações e iniciativas de caráter educativo presente e ligada a essas perspectivas no contexto brasileiro do início dos anos 60, vale aqui destacar três que se consolidaram enquanto referências para o que se tornaria a Educação Popular nas décadas seguintes tanto no âmbito nacional quanto, posteriormente, em experiências em outras regiões da América Latina: o MEB - Movimento de Educação de Base, os CPCS - Centros Populares de Cultura e o MCP - Movimento de Cultura Popular (Manfredi, 1978; Paiva, 1987).

Nesse último participou diretamente Paulo Freire, personificação e principal referência difusora do aporte hegemônico no interior do campo do sentido emancipador de educação popular 
(Mejía, 1989a). Mesmo não sendo unânime em um meio tão heterogêneo, o impacto e o reconhecimento - nacional e internacional - de sua teoria e prática, principalmente após a experiência bem-sucedida de Angicos, o levou ao MEC para trabalhar na coordenação do Programa Nacional de Alfabetização, que, por sua vez, acabou não se efetivando por conta do golpe.

É neste sentido que a prática de Paulo Freire foi aporte para educação diante dos programas de alfabetização (Lustosa, 2018), visto que o Método Paulo Freire não compreende a leitura como mera técnica, supostamente neutra e politicamente indiferente, mas enquanto força nas relações de dominação social, tendo em vista a ligação entre o acesso à palavra escrita com a conscientização a partir de cada realidade. Acessar o domínio das palavras escritas é, então, uma conquista política e um confronto à ordem vigente, levando em conta "[...] a noção de que a miséria e seu cimento, o analfabetismo, não são acidentes ou resíduo, mas parte integrada no movimento rotineiro da dominação do capital" (Schwarz, 2008, p. 81). É evidente, portanto, que apesar da urgência da formação pela alfabetização para os diferentes atores sociais nesse contexto, o central para a perspectiva freiriana não era formular apenas um método de alfabetização, mas criar formas para a emergência do povo como sujeito central de sua própria história.

Um princípio substancial para a capacidade de multiplicação de seu método se relaciona com o fato dele funcionar enquanto um conjunto de fundamentos que podem ser recriados, possibilitando sua incorporação em realidades muito distintas, consolidando o apontamento de que ser freiriano não é imitar os passos de Freire (Jara, 2018). Embora Brandão, em seu depoimento afirme que num primeiro momento a Educação Popular esteja centrada no Paulo Freire, é no segundo momento - com Paulo Freire no exílio - que ele considera que ocorre um movimento autêntico, coletivo e "muito bonito":

Você tem uma Educação Popular na América Latina [...] Não é mais o Brasil. É a América Latina inteira. [...] Paulo Freire continuava sendo uma grande referência, mas eu me lembro de todos esses encontros não tinha um guru, não. Éramos nós ali mesmo. Eu me lembro do famoso encontro de Punta del Tralca que foi feito no Chile, no finalzinho da ditadura do Pinochet. Inclusive, foi um encontro muito tenso. [...] Mas não tinha um guru. Não tinha uma pessoa que você pudesse dizer "Porra! Tal cara..." não. Era uma coletividade pensante. Eu acho o tempo mais fecundo (BRANDÃO, Entrevista, 2019).

O tempo mais fecundo da Educação Popular, contraditoriamente, se deu, de acordo com Brandão, em meio às ditaduras. Descentrado de gurus, desenvolveu-se como "uma coletividade pensante" na América Latina.

\section{CONCLUSÃO}

Essa tradição de educação popular se desenvolveu em todo continente, dando continuidade ao que Brandão chama de vocação freiriana, que vai para além das ações e obras do educador pernambucano, dizendo respeito ao significado de sua prática e também das práticas e concepções formuladas pelos seus interlocutores (Paulo, 2018). A evidente delimitação da educação assinada como popular ligada exclusivamente à prática de libertação das classes populares na América Latina tem sua origem relacionada a essa "coletividade pensante" e praticante da educação para a libertação, associada às lutas e interesses das classes populares. As práticas educativas vinculamse, portanto, aos seus contextos específicos, e só podem responder às contradições de seu tempo se estão profunda e organicamente relacionadas a elas, sem recair às mistificações dessa realidade.

A epistemologia de Freire compreende o caráter essencialmente político e materialista da educação, de acordo com Frei Betto (2008, p. 7): “[...] a cabeça pensa por onde os pés pisam. 0 mundo desigual pode ser lido pela ótica do opressor ou pela ótica do oprimido". Para Claudia Korol (2006; 2008), a educação popular fundada em um sentido político-pedagógico contra hegemônico 
e emancipatório inspirado em Freire assume processos de formação política de seus agentes, realizando ações culturais com setores populares e estimulando sua práxis a partir de eixos relacionados ao diálogo, dialética, autonomia, pergunta, subjetividade, coletividade, solidariedade, democracia, dignidade, rebeldia e transformação. Mais do que método, técnica ou teoria, essa Educação Popular é um fato político-pedagógico e ético (Jara, 1987; 2020) cujas propostas são construídas no interior das dinâmicas dos movimentos populares e leva em conta suas necessidades e objetivos (ECO, 2012). Desse modo, é meio organizativo e formativo de quem se envolve na ação transformadora de sua realidade (Barreiro, 1980). Ela é "parte do trabalho político que contribui para acumular o poder popular através do conhecimento" (Viezzer, 1989, p. 3), pois os pés que pisam o chão junto aos movimentos sociais vivem a materialidade dos confrontos e antagonismos sociais.

Cabe dizer que a preocupação com a memória de um processo coletivo de mudança a partir dos interesses das classes populares tem um papel relevante, sobretudo em momentos de aprofundamento da barbárie e do autoritarismo, nos quais tende a haver uma monopolização das narrativas que querem se construir como dominante. A busca pela identificação da história com a memória dos vencedores cria a "memória do conquistador" (Brandão, 1984), que, através da espoliação e da eliminação de outras formas de se educar e de outras memórias presentes, procura ganhar enraizamento social. Em tais momentos, as memórias contra hegemônicas precisam sobreviver porque delas provém a história e a ciência acerca da capacidade de transformação pelas mãos das classes populares.

Contribuições dos Autores: Schlindwein, I. G. C.: levantamento bibliográfico, preparação e realização de entrevista, análise e interpretação dos materiais obtidos, redação do artigo, revisão crítica relevante do conteúdo intelectual; Catini, C R.: orientação da pesquisa de mestrado do autor principal, revisão redação do artigo, crítica relevante do conteúdo intelectual. Todos os autores leram e aprovaram a versão final do manuscrito.

Aprovação Ética: Aprovado pelo Comitê de Ética em Pesquisa (CEP) da UNICAMP. CAAE: 89306318.5.0000.8142.

Agradecimentos: Agradecemos imensamente Carlos Rodrigues Brandão, com toda sua atenção ao compartilhar memórias de tantas experiências construídas coletivamente.

\section{REFERÊNCIAS}

Barreiro, J. (1980). Educação popular e conscientização. Petrópolis: Vozes.

Betto, F. (2008). Sobre Paulo Freire. In: CEPIS. Concepção de educação popular do CEPIS. São Paulo: Maxprint Editora e gráfica.

Bosi, E. (2003). O tempo vivo da memória: ensaios de psicologia social. São Paulo, SP: Ateliê.

Brandão, C. R. (1984). Pensar a prática: escritos de viagem e estudos sobre a educação. São Paulo, SP: Edições Loyola.

Brandão, C. R. (1995). Em Campo Aberto. São Paulo, SP: Cortez.

Brandão, C. R. (2002). A educação como cultura. Ed. rev. e ampl. Campinas, SP: Mercado de Letras.

Brandão, C. R. (2015a). Quando a Pedagogia tornou-se "do oprimido". Quando a Educação tornou-se "popular": um ensaio de memórias escrito a várias mentes e mãos. Disponível em: https://apartilhadavida.com.br/outros-escritos/

Brandão, C. R. (2015b). Memória Científica - Carlos Brandão. Entrevista à Marcelo Rocco. Secretaria de Comunicação TV Unicamp. (56m54s). Disponível em: https://www.youtube.com/watch?V=g IKWK xR8Y

Brandão, C. R. (2018). A Educação Popular e o CEAAL na linha do tempo: memórias e reflexões de um educador dos anos sessenta. La Piragua: Revista Latinoamericana y Caribeña de Educación Popular, 44, 1-17. 
Carrillo, A. T. (2011). Educación Popular, trayectoria y actualidad. Caracas: Universidad Bolivariana de Venezuela.

Costa, B (2010). Jether Ramalho: companheiro de muitas andanças até hoje!. In: José Ricardo Ramalho (Org.). Uma presença no tempo; a vida de Jether Ramalho. São Leopoldo, Oikos Ed..

ECO - Educación y Comunicaciones (2012). ECO En El Horizonte Latinoamericano (I): La Educación Popular Bajo La Dictadura. Santiago, Chile: ECO.

Fernandes, F. (2009). Capitalismo dependente e classes sociais na América Latina / Florestan Fernandes, 1920 - 1995. Apresentação de Ricardo Antunes. - 4a ed. rev. - São Paulo: Global.

Freire, P. (1987). Pedagogia do Oprimido, 17a ed. Rio de Janeiro, Paz e Terra.

Germano, J. W. (1997). As quarenta horas de Angicos. Educação \& Sociedade, 18(59), 389-393.

Harnecker, M., \& Uribe, G. (1972). Cuarderno de Educacion Popular № 1: Explotados y Explotadores. Editorial Nacional Quimantú. Disponível em: http://www.socialismo-chileno.org/PS/quimantu/cep.html

Jara, O. (1987). A Educação na América Latina: O Desafio de Teorizar sobre a Prática para Transformar. Lições da Nicaragua: a experiencia da esperança / [por] Ernesto Cardenal [et al.]; Carlos Rodrigues Brandão (organizador). 3. ed. Campinas, SP: Papirus.

Jara, O. (2006). Ressignifiquemos as Propostas e Práticas de Educação Popular Perante os Desafios Históricos Contemporâneos. In Educação Popular na América Latina: diálogos e perspectivas / Pedro Pontual, Timothy Ireland (organizadores). Brasília: Ministério da Educação: UNESCO.

Jara, O. (2018). "Ser freireano não é repetir os textos de Paulo Freire." - Entrevista com Oscar Jara. Entrevista concedida a Luís Gustavo Ruwer. Repórter Popular, 03 de setembro de 2018. Disponível em: http://reporterpopular.com.br/serfreireano-nao-e-repetir-os-textos-de-paulo-freire-entrevista-com-oscar-jara/

Jara, O. (2020). La Educación Popular Latinoamericana: Historia, claves éticas, políticas y pedagógicas. Santiago de Chile: Colectivo Caracol - El apañe de los piños; Editorial Quimantú.

Korol, C. (2006). Educación Como Acción Cultural Para La Libertad. In Korol, C. Caleidoscopios de Rebeldías. Argentina, Ediciones America Libre.

Korol, C. (2008). Una perspectiva feminista en la formación de los movimientos populares: La batalla simultánea contra todas las opresiones. Revista Venezolana de Estudios de la Mujer, 3(31), 27-38.

Lang, A. B. da S. G., Campos, M. C. S. de S., \& Demartini, Z. de B. F. (2010). História oral, sociologia e pesquisa: a abordagem do CERU. São Paulo, SP: Humanitas: CERU.

Lustosa, K. da S. (2018). Quando a educação é tomada como "ato subversivo": a campanha de educação popular CEPLAR e as ligas camponesas na Paraíba / Kelyana da Silva Lustosa. - Campina Grande.

Manfredi, S. M. (1978). Politica: educação popular. São Paulo, SP: Simbolo.

Manfredi, S. M. (2014). De Angicos ao Programa Nacional de Alfabetização. In: Alfabetizar e conscientizar: Paulo Freire, 50 anos de Angicos / Moacir Gadotti, organizador. 1. ed. - São Paulo: Instituto Paulo Freire.

Mejía, M. R. (1989a). Educação popular: pedagogia e dialetica. ljuí, RS: Editora Unijuí.

Mejía, M. R. (1989b). Sindicato e pedagogia: rumo a uma escola enraizada na educação popular. ljuí, RS: Editora Unijuí.

Paiva, V. P. (1987). Educação popular e educação de adultos. 5. ed. São Paulo, SP: Loyola.

Paulo, F. dos S. (2018). Pioneiros e pioneiras da Educação Popular freireana e a universidade / por Fernanda dos Santos Paulo. - São Leopoldo, RS. 
Ridenti, M. (2018). 1968 Cinquentão: rebeldia e integração. Revista Eco Pós, 21(1), e18480.

https://doi.org/10.29146/eco-pos.v21i1.18480

Rodríguez, S. (2017). Defensa de Bolívar. Biblioteca Saavedra Fajardo, 2017. Disponível em: https://www.saavedrafajardo.org/Archivos/rodriguezdefensa.pdf

Romão, J. E. (2014). Introdução: A década que queria mudar o Brasil. Alfabetizar e conscientizar: Paulo Freire, 50 anos de Angicos / Moacir Gadotti, organizador. 1. ed. - São Paulo: Instituto Paulo Freire.

Schlindwein, I. G. C. (2020). A educação popular sob o céu da história: um estudo a partir da rememoração em Walter Benjamin. Dissertação (Mestrado em Educação). Universidade Estadual de Campinas, Campinas.

Schwarz, R. (2008). Cultura e política, 1964-1969. In: o pai de família e outros estudos / Roberto Schwarz. São Paulo: Companhia das Letras.

Scocuglia, A. C. (1999). História e educação popular na Paraibrasil (1961/1970). Revista de Educação Pública, n. 14, junho/dezembro, UFMT, 1999.

Torres, C. A. (1992). A Política da Educação Não-Formal na América Latina / Carlos Alberto Torres; tradução de Lólio Lourenço de Oliveira. - Rio de Janeiro: Paz e Terra.

Viezzer, M. (1989). Educação popular feminista. Cunhary - Rio das Mulheres, Informativo da Rede Mulher - Ano II, número 4.

Recebido: 20 de Outubro de 2020 | Aceito: 2 de Agosto de 2021 | Publicado: 24 Agosto de 2021

This is an Open Access article distributed under the terms of the Creative Commons Attribution License, which permits unrestricted use, distribution, and reproduction in any medium, provided the original work is properly cited. 